\title{
What is the relevance of quality of life assessment for patients with attention impairment?
}

\author{
Karine Baumstarck ${ }^{1 *}$, Mohamed Boucekine ${ }^{1}$, Irina Klemina ${ }^{2}$, Françoise Reuter ${ }^{2}$, Valérie Aghababian ${ }^{3}$, \\ Anderson Loundou', Jean Pelletier ${ }^{2}$ and Pascal Auquier ${ }^{1}$
}

\begin{abstract}
Background: Attention disturbances are frequently observed in multiple sclerosis (MS) patients. The aim of this study was to provide new evidence regarding the suitability of using self-reported QoL information in this impaired population by exploring the construct validity, reliability, and external validity of a MS-specific quality of life (QoL) instrument.

Methods: Design: cross-sectional study. Inclusion criteria: MS patients of any disease subtype. Data collection: sociodemographic (age, gender, marital status, education level, and occupational activity) and clinical data (Expanded Disability Status Scale, disease duration); QoL (MusiQoL and SF36); and attention performance (Wechsler Memory Scale and PASAT). According to the French norms, non-impaired and impaired populations were defined. For each population, suitability indices were provided to quantify how the structures matched with the initial structure of the reference population assessed in the validation study.
\end{abstract}

Findings: One hundred and twenty-four consecutive patients were enrolled. The factor analysis performed in the impaired populations showed that the questionnaire structure adequately matched the initial structure of the MusiQoL. The unidimensionality of the dimensions was preserved, and the internal/external validity indices were close to those of the reference population.

Conclusions: Our study suggests that attention impairment dysfunction did not compromise the reliability and validity of the self-reported QoL questionnaires.

Keywords: Attention dysfunction, Multiple sclerosis, Quality of life, Validity, Reliability, MusiQoL

\section{Introduction}

The use of self-reported outcomes in subjects with cognitive dysfunction is of particular concern [1]. The main argument against using self-reported quality of life (QoL) information from patients with cognitive dysfunction is that QoL instruments were not developed for use with cognitively impaired individuals. Some authors argue that cognitively impaired individuals suffering from multiple sclerosis (MS) are unable to produce valid QoL measures $[2,3]$, whereas other studies have suggested that cognitive decline in these patients does not compromise the reliability/validity of self-reported health measures [4-7]. In these previous studies, the assessment of cognitive function

\footnotetext{
* Correspondence: karine.baumstarck@univ-amu.fr

${ }^{1}$ Self-perceived Health Assessment Research Unit, School of Medicine,

Université de la Méditerranée, Marseille, France

Full list of author information is available at the end of the article
}

focused on aspects of memory [5,7] and executive functions [6].

Attention plays a role in cognitive processing and learning. Attention as a basic cognitive function represents an essential part of conscious perception and higher order cognitive functions and plays an important role in normal functioning. Attention is a broad term that is used to designate the processes that mediate the appropriate allocation of cognitive resources to relevant stimuli, such as objects, locations or moments. The limitation of this capacity may result from deficits in the automatic or controlled processing of information, as well as the incapacity to store and manipulate temporary information, the function known as working memory. In MS patients, cognitive performance is globally affected and impacts divided attention, focused attention, sustained attention, attentional flexibility, and response speed $[8,9]$.

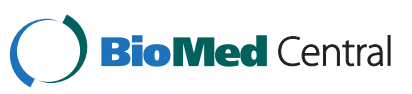


Despite the high occurrence of working memory and attention disturbances in MS patients [10,11], even during the early stages of the disease [12], no study has specifically examined the extent to which MS patients with attention dysfunction can validly self-report their QoL. Herein, we provide new evidence regarding the suitability of using selfreported QoL information in this impaired population. The aim of this study was to explore the construct validity, reliability and external validity of a MS-specific QoL instrument in MS subjects with or without attention impairment.

\section{Methodology}

This study relied on a cross-sectional design and was performed in the neurology department of a public French academic teaching hospital (Marseille, France). The inclusion criteria were as follows: a MS diagnosis according to the McDonald criteria [13], age $\geq 18$ years, any subtype of MS, outpatient status, no neurological disease (other than MS), no history of severe mental illness (except depressive disorder), no dementia (Mini Mental State Examination score $<24$ ), no history of alcohol/drug abuse, and native French-speaking. The French Ethics Committee approved the study (Comité Consultatif de Protection des Personnes dans la Recherche Biomédicale, Marseille 2, France) and patients gave their written consent to participate. Sociodemographic (age, gender, marital status, education level, and occupational activity) and clinical (MS subtype and disease duration) data were recorded for each patient. MS disability was assessed using the Expanded Disability Status Scale (EDSS).

QoL was assessed using the French version of the Multiple Sclerosis International Quality of Life questionnaire (MusiQoL) and the Short Form 36 (SF36). The MusiQoL is a well-validated MS-specific questionnaire that describes the nine dimensions and yields a global index score: activity of daily living (ADL), psychological well-being (PWB), symptoms (SPT), relationships with friends $(\mathrm{RFr})$, relationships with family (RFa), relationships with health care system (RHCS), sentimental and sexual life (SSL), coping (COP), and rejection (REJ). The SF36 is a generic questionnaire [14] describing eight subscales: physical function (PF), social function (SF),

Table 1 Suitability indices of construct validity and external validity according to the attention status

\begin{tabular}{|c|c|c|c|c|}
\hline \multirow[b]{2}{*}{ Construct validity } & \multicolumn{2}{|c|}{ Attention_WMS } & \multicolumn{2}{|l|}{ PASAT } \\
\hline & NI 75 & 139 & NI 32 & 173 \\
\hline$\%$ of identified factors & 88,9 & 88,9 & 88,9 & 100 \\
\hline$\%$ of well-projected items & 57,1 & 80,6 & 83,9 & 100 \\
\hline$\%$ of dimensions with IIC non exceeded 0,2 from ref & 44,4 & 77,8 & 77,8 & 44,4 \\
\hline$\%$ of dimensions with IDV non exceeded 0,2 from ref & 33,3 & 22,2 & 0 & 44,4 \\
\hline$\%$ of dimensions with IDV $<\| C$ & 88,9 & 77,8 & 77,8 & 66,7 \\
\hline$\%$ of dimensions with Cronbach's alpha coefficients $>=0,7$ or $>=$ ref & 77,8 & 66,7 & 77,8 & 77,8 \\
\hline$\%$ of dimensions with INFIT ranged $[0,7-1,3]$ & 83,3 & 83,3 & 66,7 & 44,4 \\
\hline$\%$ of dimensions with $\mathrm{MV}<10 \%$ from ref & 100 & 88,9 & 88,9 & 88,9 \\
\hline$\%$ of dimensions with Floor $<10 \%$ from ref & 77,8 & 33,3 & 77,8 & 55,6 \\
\hline$\%$ of dimensions with Ceiling $<10 \%$ from ref & 66,7 & 77,8 & 66,7 & 66,7 \\
\hline Total & 71,8 & 69,7 & 70,6 & 68,9 \\
\hline External validity & NI 75 & 139 & NI 32 & 173 \\
\hline SF36: $\%$ of dimensions meeting three conditions* & 88,9 & 88,9 & 55,6 & 88,9 \\
\hline Age: $\%$ of dimensions with correlation coefficient $<0,40$ & 100 & 100 & 100 & 100 \\
\hline EDSS: \% of dimensions meeting two conditions** & 100 & 88,9 & 88,9 & 88,9 \\
\hline MS duration: $\%$ of dimensions with correlation coefficient $<0,40$ & 100 & 100 & 100 & 100 \\
\hline Gender: \% of dimensions with $E S<0,2$ from ref & 88,9 & 100 & 100 & 100 \\
\hline Educational level: \% of dimensions with $\mathrm{ES}<0,2$ from ref & 55,6 & 44,4 & 66,7 & 44,4 \\
\hline Marital status: $\%$ of dimensions with $\mathrm{ES}<0,2$ from ref & 100 & 88,9 & 77,8 & 100 \\
\hline Occupational status: $\%$ of dimensions with $\mathrm{ES}<0,2$ from ref & 55,6 & 55,6 & 55,6 & 44,4 \\
\hline Total & 86,1 & 83,3 & 80,6 & 83,3 \\
\hline
\end{tabular}

* MusiQoL and SF36: the three conditions were: i) correlation coefficient between ADL and PF or RP or V higher than 0,50 and stronger than the other correlations; ii) correlation coefficient between PWB and $\mathrm{MH}$ higher than 0,50 and stronger than the other correlations; iii) all other correlation coefficients inferior to 0,40 .

** MusiQoL and EDSS: the two conditions were: i) correlation coefficient between ADL and EDSS >0,4 and stronger than the other correlations; ii) all other correlation coefficients inferior to 0,40 , The score was $100 \%$ when all the dimensions met the condition.

$\mathrm{NI}$ non impaired, I impaired, Ref reference population. 
role physical (RP), role emotional (RE), mental health $(\mathrm{MH})$, vitality $(\mathrm{V})$, bodily pain $(\mathrm{BP})$, and general health (GH). Two composite scores (physical and mental, PCSSF36 and MCS-SF36) were also calculated.

Attention performance was measured using two tests: the French version of the Paced Auditory Serial Addition Test (PASAT) [15] and the attention/concentration subscale of the French version of the Wechsler Memory Scale (attention_WMS) [16]. The attention_WMS score was calculated using 3 subtests (mental control, digit span, and visual memory). By comparing with French normative values according to age group [16], a patient was considered cognitively impaired if their score was more than 1 standard deviation (SD) below the normative value. The PASAT score was generated using the PASAT$3 \mathrm{~s}$ version of the test (number of correct responses). By comparing with French normative values according to sex, age, and educational level [17], a patient was considered to be cognitively impaired if their PASAT score was more than $1 \mathrm{SD}$ below the normative value.

\section{Statistical analysis}

Statistical analyses were performed on the populations defined above using the same procedure reported in the initial validation publication (reference population) [18]. For each group, psychometric properties were compared to those reported from the reference population. The structures of the MusiQoL were explored in the nonimpaired and impaired populations using principal component factor analyses with varimax rotation $[19,20]$ to determine how these structures matched with the initial structure of the MusiQoL. For each population, the proportion of factors identified from the initial ninefactor structure of MusiQoL and the proportion of items projected to their initial dimension were retrieved.

The multidimensional structure (construct validity) was verified using the multi-trait/multi-item analysis program [21]. Internal structural validity was assessed by calculating item-dimension correlations. Item internal consistency (IIC) was calculated by correlating each item with its scale, and item discriminant validity (IDV) was

Table 2 Internal structural validity/reliability/unidimensionality according to the cognitive status

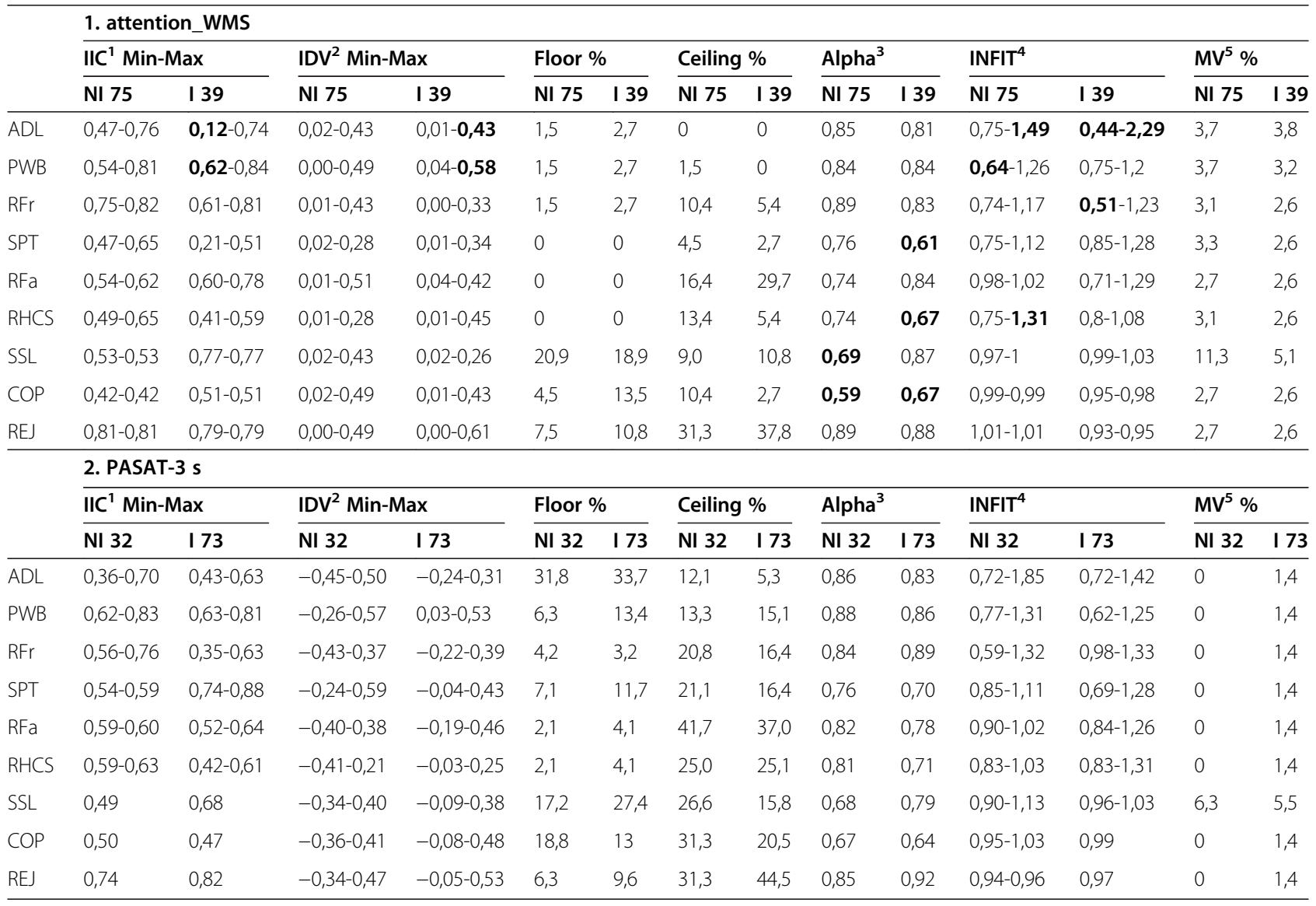

$A D L$ activity of daily living, $P W B$ psychological well-being, $R F r$ relationships with friends, $S P T$ symptoms, RFa relationships with family, $R H C S$ relationships with health care system, SSL sentimental and sexual life, COP coping, REJ rejection.

NI non-impaired, I impaired.

${ }^{1}$ Item-Internal Consistency, ${ }^{2}$ Item Discriminant Validity, ${ }^{3}$ Cronbach's alpha, ${ }^{4}$ Rasch statistics, ${ }^{5}$ Missing Values.

Bold values: unsatisfactory values. 
assessed by determining the extent to which items correlated with the dimension they were hypothesized to represent compared to correlations with other dimensions. Floor and ceiling effects were determined to assess the distribution of the responses. For each dimension, internal consistency reliability was evaluated using Cronbach's alpha coefficient [22].

The unidimensionality of each dimension was calculated by computing item goodness-of-fit statistics (INFIT) issued from Rasch analyses [23]. INFIT values ranging from 0.7 to 1.2 ensure that all scale items tend to measure the same concept.

To assess external validity, Spearman's correlation coefficients were used to determine relationships between the MusiQoL and SF36 dimensions in each group, and the associations between MusiQoL dimension scores and sociodemographic and clinical features were reported as in the validation study. For qualitative variables, the mean dimension scores of the MusiQoL were compared across patient groups (e.g., gender, educational level, marital status, and occupational status) using oneway analysis of variance. Quantitative variables (e.g., age, EDSS score, and MS duration) were analyzed using
Spearman's correlation coefficients. Acceptability was assessed by calculating the percentage of missing data per dimension. Data analyses were performed using SPSS 11.0, MAP-R, LISREL and WINSTEP software.

To quantify how each of the 4 structures matched with the initial structure (reference structure), suitability indices were calculated in accordance with a previous study [7]. Decision rules were established by experts in QoL and used to define satisfactory properties according to appropriate standards $[19,20]$. The means of different proportions were calculated to produce the suitability index of the 'construct validity' and the suitability index of the 'external validity'.

\section{Results}

A total of 124 patients participated in the study. The mean age was 45 years (SD 11), $71(57,3 \%)$ of the patients were women, and $58(47,2 \%)$ had more than 12 years of education. MS subtypes included 61 (49,2\%) secondary progressive, 36 (29,0\%) relapsing-remitting, 20 $(16,1 \%)$ primary progressive, and $7(5,6 \%)$ clinically isolated syndromes. The EDSS median was 4.75 (minimum 1.00, maximum 8.00), and the median disease duration

Table 3 Correlations between MusiQoL and SF36 scores according to the cognitive status based on Wechsler Memory Scale

\begin{tabular}{|c|c|c|c|c|c|c|c|c|c|c|c|}
\hline SF36 & & $A D L$ & PWB & $\mathrm{RFr}$ & SPT & $\mathrm{RFa}$ & RHCS & SSL & COP & REJ & index \\
\hline \multirow[t]{2}{*}{ Physical functioning } & $\mathrm{NI}$ & $0,721^{* *}$ & 0,161 & $-0,071$ & $-0,028$ & 0,022 & 0,223 & 0,219 & 0,130 & 0,124 & $0,267^{*}$ \\
\hline & । & $0,512^{* *}$ & 0,332 & $-0,157$ & 0,166 & $-0,202$ & 0,041 & 0,206 & 0,261 & 0,150 & 0,303 \\
\hline \multirow[t]{2}{*}{ Social functioning } & $\mathrm{NI}$ & $0,353^{* *}$ & 0,211 & 0,149 & $0,405^{* *}$ & 0,136 & $-0,085$ & 0,222 & $0,398^{* *}$ & 0,156 & $0,361^{* *}$ \\
\hline & I & 0,294 & $0,351^{*}$ & 0,004 & 0,052 & 0,173 & $0,456^{* *}$ & 0,258 & 0,220 & 0,333 & $0,524^{* *}$ \\
\hline \multirow[t]{2}{*}{ Role physical } & $\mathrm{NI}$ & $0,564^{* *}$ & 0,215 & 0,027 & $0,245^{*}$ & $-0,147$ & 0,015 & 0,022 & 0,160 & $0,266^{*}$ & 0,233 \\
\hline & I & 0,061 & $-0,066$ & 0,029 & $-0,047$ & $-0,083$ & 0,075 & $-0,216$ & 0,091 & 0,202 & 0,014 \\
\hline \multirow[t]{2}{*}{ Role emotional } & $\mathrm{NI}$ & $0,285^{*}$ & $0,372^{* *}$ & 0,051 & $0,444^{* *}$ & 0,027 & $-0,212$ & $0,284^{*}$ & 0,085 & 0,096 & $0,336^{* *}$ \\
\hline & I & 0,211 & 0,245 & 0,164 & 0,206 & 0,001 & 0,052 & 0,118 & $0,376^{*}$ & 0,266 & $0,395^{*}$ \\
\hline \multirow[t]{2}{*}{ Mental health } & $\mathrm{NI}$ & $0,277^{*}$ & $0,728^{* *}$ & 0,090 & $0,249 *$ & 0,056 & 0,037 & 0,192 & $0,437^{* *}$ & 0,221 & $0,514^{* *}$ \\
\hline & I & 0,296 & $0,662^{* *}$ & 0,097 & 0,178 & 0,306 & 0,120 & $0,380^{*}$ & $0,403^{*}$ & 0,320 & $0,686^{* *}$ \\
\hline \multirow[t]{2}{*}{ Vitality } & $\mathrm{NI}$ & $0,609^{* *}$ & $0,319^{* *}$ & $-0,129$ & $0,379 * *$ & $-0,165$ & 0,108 & 0,063 & 0,132 & 0,117 & 0,222 \\
\hline & I & $0,483^{* *}$ & 0,299 & $-0,099$ & 0,207 & $-0,089$ & 0,207 & 0,257 & 0,103 & 0,156 & $0,353^{*}$ \\
\hline \multirow[t]{2}{*}{ Bodily pain } & $\mathrm{NI}$ & $0,389 * *$ & $0,286^{*}$ & $-0,034$ & $0,242^{*}$ & $-0,244^{*}$ & $-0,003$ & 0,062 & 0,089 & 0,136 & 0,218 \\
\hline & I & 0,262 & $0,405^{*}$ & $-0,119$ & $0,406^{*}$ & 0,031 & $-0,028$ & 0,029 & $-0,010$ & 0,279 & 0,313 \\
\hline \multirow[t]{2}{*}{ General health } & $\mathrm{NI}$ & $0,482^{* *}$ & 0,233 & 0,011 & $0,266^{*}$ & 0,181 & $-0,030$ & 0,242 & $0,259^{*}$ & 0,082 & $0,309^{*}$ \\
\hline & I & $0,564^{* *}$ & 0,309 & $-0,012$ & 0,127 & $-0,317$ & 0,128 & 0,283 & 0,221 & 0,050 & 0,286 \\
\hline \multirow[t]{2}{*}{ MCS } & $\mathrm{NI}$ & $0,258^{*}$ & $0,620 * *$ & 0,090 & $0,486^{* *}$ & 0,057 & $-0,127$ & 0,228 & $0,372^{* *}$ & 0,171 & $0,454^{* *}$ \\
\hline & 1 & 0,301 & $0,547^{* *}$ & 0,187 & 0,180 & 0,261 & 0,254 & $0,375^{*}$ & $0,440^{* *}$ & $0,379^{*}$ & $0,721^{* *}$ \\
\hline \multirow[t]{2}{*}{ PCS } & $\mathrm{NI}$ & $0,721^{* *}$ & 0,034 & $-0,028$ & 0,149 & $-0,105$ & 0,153 & 0,081 & 0,090 & 0,144 & 0,165 \\
\hline & I & $0,495^{* *}$ & 0,161 & $-0,234$ & 0,216 & $-0,404^{*}$ & $-0,041$ & $-0,021$ & $-0,002$ & 0,105 & 0,049 \\
\hline
\end{tabular}

$A D L$ activity of daily living, $P W B$ psychological well-being, $R F r$ relationships with friends, SPT symptoms, RFa relationships with family, RHCS relationships with health care system, SSL sentimental and sexual life, COP coping, REJ rejection.

MCS mental composite score, PCS physical composite score.

NI non-impaired, I impaired.

Spearman rank correlation coefficients were presented.

Bold values: $p<0.05,{ }^{*} p$-value $<0.05,{ }^{* *} p$-value $<0.01$. 
was 9.86 years (minimum 0, maximum 31). After comparison to the French normative values, 75 nonimpaired and 39 impaired individuals were identified based on the attention_WMS, and 32 non-impaired and 73 impaired individuals were identified based on the PASAT.

\section{Construct validity}

The 9-factor structure of the MusiQoL was clearly detected in the PASAT-impaired population, and 8 factors were detected in the attention_WMS-impaired population (the REJ dimension was not detected). The percentage of items well-projected to their initial dimension was higher in the impaired populations (range: 80,6 to $100 \%)$ compared to the non-impaired populations (Additional files 1 and 2). The proportion of dimensions with IIC and the proportion of dimensions with IDV that were greater than 0.2 from the reference dimension were moderately satisfactory. In contrast, the correlation of each item with its associated dimension was higher than with the others in 6 dimensions in the PASATimpaired population and 7 dimensions in the attention_WMS-impaired populations. Cronbach's alpha coefficients were satisfactory in at least 6 of 9 dimensions in the two impaired populations. The INFIT statistics were satisfactory in the attention_WMS-impaired population, but less satisfactory for the PASAT-impaired group. The proportions of dimensions with floor and ceiling effects less than $10 \%$ from the reference are described in Table 1. Additional details are provided in Table 2. The suitability indices of construct validity in the impaired populations were populations were detailed in Table 1.

\section{External validity}

Eight dimensions satisfied the 3 conditions defining the suitability of relationships between MusiQoL and SF36 scores, both for the PASAT- and attention_WMS-impaired populations (Tables 3 and 4). The suitability indices of age, disease duration, EDSS, gender, and marital status were satisfactory. Associations between the MusiQoL scores and educational level and occupational status were less satisfactory (Additional files 3 and 4). In summary, the suitability indices of external validity in the non-impaired populations were $83 \%$ (Table 1).

\section{Discussion/conclusion}

As reported in previous studies [4,6,7,24], our results support the conclusion that cognitively impaired MS

Table 4 Correlations between MusiQoL and SF36 scores according to the cognitive status based on PASAT

\begin{tabular}{|c|c|c|c|c|c|c|c|c|c|c|c|}
\hline SF36 & & ADL & PWB & RFr & SPT & RFa & RHCS & SSL & COP & REJ & index \\
\hline \multirow[t]{2}{*}{ Physical functioning } & $\mathrm{NI}$ & $0,511^{* *}$ & $-0,069$ & $-0,047$ & $-0,206$ & 0,096 & 0,288 & $0,454^{*}$ & 0,113 & 0,215 & 0,264 \\
\hline & I & $0,518^{* *}$ & 0,160 & $-0,170$ & 0,020 & $-0,023$ & 0,121 & 0,049 & 0,097 & $-0,152$ & 0,104 \\
\hline \multirow[t]{2}{*}{ Social functioning } & $\mathrm{NI}$ & $0,377^{*}$ & 0,211 & $-0,088$ & $0,404^{*}$ & $-0,128$ & $-0,034$ & 0,155 & $0,403^{*}$ & $-0,047$ & 0,289 \\
\hline & I & $0,325^{* *}$ & $0,329 * *$ & 0,087 & 0,219 & 0,158 & 0,080 & 0,154 & $0,326^{* *}$ & $0,321^{* *}$ & $0,404^{* *}$ \\
\hline \multirow[t]{2}{*}{ Role physical } & $\mathrm{NI}$ & $0,481^{* *}$ & 0,072 & $-0,411^{*}$ & 0,092 & $-0,324$ & $-0,143$ & 0,124 & 0,100 & 0,166 & 0,005 \\
\hline & 1 & $0,398^{* *}$ & 0,153 & 0,073 & 0,162 & $-0,079$ & 0,195 & $-0,097$ & 0,212 & 0,212 & 0,222 \\
\hline \multirow[t]{2}{*}{ Role emotional } & $\mathrm{NI}$ & 0,289 & $0,470 *$ & $-0,343$ & 0,306 & $-0,171$ & $-0,389 *$ & 0,227 & 0,159 & 0,185 & 0,224 \\
\hline & I & 0,237 & $0,369 * *$ & $0,262 *$ & $0,365^{* *}$ & 0,200 & $-0,035$ & $0,284^{*}$ & 0,155 & 0,196 & $0,438^{* *}$ \\
\hline \multirow[t]{2}{*}{ Mental health } & $\mathrm{NI}$ & 0,260 & $0,734^{* *}$ & $-0,163$ & $0,480 * *$ & $-0,023$ & $-0,118$ & 0,015 & $0,401^{*}$ & $-0,099$ & $0,433^{*}$ \\
\hline & I & $0,304^{*}$ & $0,709 * *$ & 0,216 & 0,184 & $0,296 *$ & 0,215 & $0,348^{* *}$ & $0,343^{* *}$ & $0,281^{*}$ & $0,632^{* *}$ \\
\hline \multirow[t]{2}{*}{ Vitality } & $\mathrm{NI}$ & $0,621^{* *}$ & 0,353 & $-0,236$ & $0,548^{* *}$ & $-0,187$ & 0,178 & 0,127 & 0,023 & 0,033 & 0,356 \\
\hline & I & $0,540 * *$ & 0,216 & $-0,104$ & 0,086 & $-0,236$ & $0,248 *$ & 0,069 & 0,191 & 0,024 & 0,188 \\
\hline \multirow[t]{2}{*}{ Bodily pain } & $\mathrm{NI}$ & $0,483^{* *}$ & 0,351 & $-0,161$ & $0,390 *$ & $-0,318$ & $-0,159$ & 0,221 & 0,248 & 0,302 & 0,351 \\
\hline & I & $0,348^{* *}$ & $0,261 *$ & $-0,124$ & $0,296 *$ & $-0,165$ & 0,042 & $-0,032$ & $-0,057$ & $-0,006$ & 0,143 \\
\hline \multirow[t]{2}{*}{ General health } & $\mathrm{NI}$ & $0,602^{* *}$ & 0,149 & $-0,107$ & 0,245 & 0,108 & 0,122 & 0,290 & 0,096 & $-0,032$ & 0,239 \\
\hline & I & $0,449 * *$ & 0,216 & $-0,128$ & 0,226 & $-0,038$ & 0,121 & 0,157 & $0,318^{* *}$ & $-0,023$ & 0,245 \\
\hline \multirow[t]{2}{*}{ MCS } & $\mathrm{NI}$ & 0,164 & $0,645^{* *}$ & $-0,288$ & $0,528^{* *}$ & $-0,059$ & $-0,202$ & 0,034 & 0,216 & $-0,132$ & 0,251 \\
\hline & I & $0,328^{* *}$ & $0,615^{* *}$ & $0,295^{*}$ & $0,320 *$ & 0,229 & 0,093 & $0,324^{*}$ & $0,423^{* *}$ & $0,388^{* *}$ & $0,637^{* *}$ \\
\hline \multirow[t]{2}{*}{$\overline{P C S}$} & $\mathrm{NI}$ & $0,679 * *$ & $-0,192$ & $-0,154$ & $-0,044$ & $-0,139$ & 0,197 & 0,336 & 0,107 & 0,227 & 0,208 \\
\hline & I & $0,542^{* *}$ & 0,018 & $-0,281^{*}$ & 0,191 & $-0,324^{* *}$ & 0,063 & $-0,131$ & 0,006 & $-0,161$ & $-0,055$ \\
\hline
\end{tabular}

$A D L$ activity of daily living, PWB psychological well-being, $R F r$ relationships with friends, SPT symptoms, $R F a$ relationships with family, $R H C S$ relationships with health care system, SSL sentimental and sexual life, COP coping, REJ rejection.

MCS mental composite score, PCS physical composite score.

NI non-impaired, I impaired.

Spearman rank correlation coefficients were presented.

Bold values: $\mathrm{p}<0.05,{ }^{*} \mathrm{p}$-value $<0.05,{ }^{* *} \mathrm{p}$-value $<0.01$ 
patients, as defined by attention dysfunction, reliably and consistently answer the MusiQoL questionnaire. The suitability indices of the impaired populations were close to those of the non-impaired populations, and they could be considered completely acceptable considering the small sample size of some of the defined populations. The assessment of QoL in MS patients could be more widely used without concern over the adequacy of this approach for cognitively impaired patients.

Some strengths and limitations of the current study should be considered:

i) Considering only one type of dysfunction may not have accurately reflected global cognitive functioning. It has been well documented that it is unusual to observe one deficit in isolation in clinical practice. However, there is little consensus on the definition of 'global' cognitive dysfunction [25]. Despite this limitation, the findings of the present study support the relevance of self-reported quality of life assessments for patients with cognitive disorders. Future studies should provide similar explorations in MS populations with cognitive dysfunction defined with other definitions integrating combination of different composites.

ii) We did not consider factors previously associated to cognitive performance, such as depression [26], fatigue [27], and MS medications [28]. However, the aim of this study was to provide evidence supporting the conclusion that cognitively impaired MS patients reliably answer a self-reported QoL questionnaire regardless of the presence or absence of other factors that could have influenced their performance.

iii) The suitability indices used to define satisfactory properties relied on debatable decision rules and non-standardized calculation methods. Analyses of sensitivity should be performed.

iv) Replication of these findings in larger groups of patients is required.

v) Similar studies should be performed in other populations suffering from cognitive impairment, such as severe mental illness and elderly individuals, to determine whether these findings are specific to patients with MS.

\section{Additional files}

Additional file 1: Construct validity according to the cognitive status defined from the attention_WMS score.

Additional file 2: Construct validity according to the cognitive status defined from the PASAT score.

Additional file 3: Associations between MusiQoL dimension scores and sociodemographic characteristics according to the cognitive status based on Wechsler Memory Scale.
Additional file 4: Associations between MusiQoL dimension scores and sociodemographic characteristics according to the cognitive status based on PASAT.

\section{Competing interests}

The authors declare that they have no competing interests.

\section{Authors' contributions}

Conception and design: PA, JP. Study coordination: PA, JP, KB. Inclusion and clinical data collection: IK, JP. Acquisition of cognitive data: FR, VA. Analysis of data: KB, MB, AL. Interpretation of data: KB, PA, JP, FR, VA. Drafting and writing of manuscript: KB, PA. Revision of manuscript: PA, JP, FR, VA, IK. All authors read and approved the final manuscript.

\section{Acknowledgements}

The authors are grateful to all the patients for their participation in the study. The authors thank Jessica Fernandez for her consequent contribution for the statistical analyses.

This work was supported by institutional grants from the French 2004 Programme Hospitalier Recherche Clinique and the French 2009 Institut de Recherche en Santé Publique (Concepts, Usages et Déterminants en Qualité de Vie, CUD-QV). The sponsor was represented by Assistance Publique, Hôpitaux de Marseille (Marseille, France). The funders had no role in study design, data collection and analysis, decision to publish, or manuscript preparation.

\section{Author details}

${ }^{1}$ Self-perceived Health Assessment Research Unit, School of Medicine, Université de la Méditerranée, Marseille, France. ${ }^{2}$ Departments of Neurology and CRMBM CNRS6612, Timone University Hospital, APHM, Marseille, France. ${ }^{3}$ EA 3273 Psychology of Cognition, Language, and Emotion Research Centre, Aix-Marseille University, Marseille, France.

Received: 15 February 2013 Accepted: 23 April 2013

Published: 25 April 2013

\section{References}

1. Riemsma RP, Forbes CA, Glanville JM, Eastwood AJ, Kleijnen J: General health status measures for people with cognitive impairment: learning disability and acquired brain injury. Health Technol Assess 2001, 5(6):1-100.

2. Goverover $Y$, Chiaravalloti N, DeLuca J: The relationship between selfawareness of neurobehavioral symptoms, cognitive functioning, and emotional symptoms in multiple sclerosis. Mult Scler 2005, 11(2):203-212.

3. Benedict RH, Cox D, Thompson LL, Foley F, Weinstock-Guttman B, Munschauer F: Reliable screening for neuropsychological impairment in multiple sclerosis. Mult Scler 2004, 10(6):675-678.

4. Gold SM, Schulz H, Monch A, Schulz KH, Heesen C: Cognitive impairment in multiple sclerosis does not affect reliability and validity of self-report health measures. Mult Scler 2003, 9(4):404-410.

5. Marrie RA, Miller DM, Chelune GJ, Cohen JA: Validity and reliability of the MSQLI in cognitively impaired patients with multiple sclerosis. Mult Scler 2003, 9(6):621-626.

6. Baumstarck K, Pelletier J, Aghababian V, Reuter F, Klemina I, Berbis J, Loundou A, Auquier P: Is the concept of quality of life relevant for multiple sclerosis patients with cognitive impairment? Preliminary results of a cross-sectional study. PLoS One 2012, 7(1):e30627. doi:10.1371/journal. pone.0030627.

7. Baumstarck K, Reuter F, Boucekine M, Aghababian V, Klemina I, Loundou A, Pelletier J, Auquier P: Relevance of quality of life assessment for multiple sclerosis patients with memory impairment. PLoS One 2012, 7(12):e50056.

8. De Sonneville LM, Boringa JB, Reuling IE, Lazeron RH, Ader HJ, Polman CH: Information processing characteristics in subtypes of multiple sclerosis. Neuropsychologia 2002, 40(11):1751-1765.

9. McCarthy M, Beaumont JG, Thompson R, Peacock S: Modality-specific aspects of sustained and divided attentional performance in multiple sclerosis. Arch Clin Neuropsychol 2005, 20(6):705-718.

10. Krupp LB, Sliwinski M, Masur DM, Friedberg F, Coyle PK: Cognitive functioning and depression in patients with chronic fatigue syndrome and multiple sclerosis. Arch Neurol 1994, 51(7):705-710. 
11. Zakzanis KK: Distinct neurocognitive profiles in multiple sclerosis subtypes. Arch Clin Neuropsychol 2000, 15(2):115-136.

12. Feuillet L, Reuter F, Audoin B, Malikova I, Barrau K, Cherif AA, Pelletier J: Early cognitive impairment in patients with clinically isolated syndrome suggestive of multiple sclerosis. Mult Scler 2007, 13(1):124-127.

13. Polman CH, Wolinsky JS, Reingold SC: Multiple sclerosis diagnostic criteria: three years later. Mult Scler 2005, 11(1):5-12.

14. Leplege A, Ecosse E, Verdier A, Perneger TV: The French SF-36 health survey: translation, cultural adaptation and preliminary psychometric evaluation. J Clin Epidemiol 1998, 51(11):1013-1023.

15. Gronwall DM: Paced auditory serial-addition task: a measure of recovery from concussion. Percept Mot Skills 1977, 44(2):367-373.

16. Wechsler D: WMS-R Echelle clinique de Mémoire de Wechsler-Révisée. Paris: Les Editions du Centre de Psychologie Appliquée; 1991.

17. Reuter F, Baumstarck-Barrau K, Loundou A, Pelletier J, Auquier P: Paced auditory serial addition test: normative data in a French population. Rev Neurol (Paris) 2010, 166(11):944-947.

18. Simeoni MC, Auquier $P$, Fernandez $O$, Flachenecker $P$, Stecchi $S$, Constantinescu C, Idiman E, Boyko A, Beiske A, Vollmer T, et al: Validation of the multiple sclerosis international quality of life questionnaire. Mult Scler 2008, 14(2):219-230.

19. Juniper EF, Guyatt GH, Mesbah M, Ravaud P: Quality of life and pharmacoeconomics in clinical trials. Philadelphia: Lippincott-Raven; 1996.

20. Nunnaly JC, Bernstein IC: Psychometric theory. New York: Mc Graw-Hill; 1994.

21. Ware JE, Harris WJ, Gandek B, Rogers BW: MAP-R for windows: Multitrait-multi-item analysis program - revised User's guide. Boston: Health Assessment Lab; 1997.

22. Cronbach $\sqcup$ : Coefficient alpha and the internal structure of tests. Psychometrika 1951, 16:297-334.

23. Wright BD, Stone MH: Best test design: Rasch measurement. Chicago: Mesa press; 1979.

24. Marrie RA, Goldman M: Validity of performance scales for disability assessment in multiple sclerosis. Mult Scler 2007, 13(9):1176-1182.

25. Achiron A, Barak Y: Cognitive changes in early MS: a call for a common framework. J Neurol Sci 2006, 245(1-2):47-51.

26. Arnett PA, Randolph JJ: Longitudinal course of depression symptoms in multiple sclerosis. J Neurol Neurosurg Psychiatry 2006, 77(5):606-610.

27. Debouverie M, Pittion-Vouyovitch S, Brissart H, Guillemin F: Physical dimension of fatigue correlated with disability change over time in patients with multiple sclerosis. J Neurol 2008, 255(5):633-636.

28. Oken BS, Flegal K, Zajdel D, Kishiyama SS, Lovera J, Bagert B, Bourdette DN: Cognition and fatigue in multiple sclerosis: potential effects of medications with central nervous system activity. J Rehabil Res Dev 2006 43(1):83-90.

doi:10.1186/1477-7525-11-70

Cite this article as: Baumstarck et al.: What is the relevance of quality of life assessment for patients with attention impairment?. Health and Quality of Life Outcomes 2013 11:70.

\section{Submit your next manuscript to BioMed Central and take full advantage of:}

- Convenient online submission

- Thorough peer review

- No space constraints or color figure charges

- Immediate publication on acceptance

- Inclusion in PubMed, CAS, Scopus and Google Scholar

- Research which is freely available for redistribution 